\title{
III, ERes, and Ares-A Reserves Comparison
}

\author{
JUNE L. POWER \\ Mary Livermore Library, The University of North Carolina at Pembroke, Pembroke, NC
}

A comparison of the pros and cons of three different reserves systems-Innovative's Millennium software, Docutek's Eres, and Atlas Systems Ares-as implemented at the University of North Carolina at Pembroke.

KEYWORDS Reserves, software, automation, comparison

\section{INTRODUCTION}

Founded in 1887 as the Croatan Normal School, UNCP is a smaller branch of the UNC System (with an full-time enrollment of about 6,500), yet with awarded diversity and a historical dedication to individualized service. Our dedication to services drives our approach to course reserves, which is to encourage its usage as much as possible as a way to save faculty member time and ease student access to needed materials. In working to accomplish this goal, we have sought a course reserves system that facilitates services, as well as takes into account our individual staffing needs at the library.

\section{ACCESS SERVICES AT UNCP}

The Access Services department at UNCP is comprised of circulation, reserves, stacks management, and document delivery. There are five full-time staff members who carry out the access services duties. There is a daytime circulation staff position, two positions that rotate weekends and alternate days and nights, and two document delivery positions. One of the swing shift staff positions is assigned responsibility for managing course reserves, meaning that reserves management is even more challenging due to the

Address correspondence to June L. Power, MLIS, Access Services/Reference Librarian, Mary Livermore Library, The University of North Carolina at Pembroke, P.O. Box 1510, Pembroke, NC 28372. E-mail: june.power@uncp.edu 
schedule variations. Scheduling was a primary factor in our decision making due to the need to be highly organized in processing reserves among different staff members across different shifts. Since a lot of our reserves processing involves scanning materials for electronic reserves, document delivery staff are cross-trained to assist as needed with scanning. Experienced library assistants may also assist with such tasks as labeling and organizing the physical reserves.

\section{FACULTY AND STUDENT EXPECTATIONS}

The expectations of our patrons were the other primary factor driving our reserves systems decisions. Both faculty and students want a reserves system that is as effortless as possible, and it is part of our service doctrine to make things as effortless as possible for our patrons. Faculty also place a prime importance on the timeliness of reserves processing. While we process reserves year round, we often see a large rush of requests at the beginning of each semester, to be ready as immediately as possible, from a faculty perspective. We guarantee 24-48 hour turnaround time on reserves processing and so need a system that helps us to meet this expectation. Low costs are another expectation. For students this means paying for copies of reserve materials. For faculty, costs come in the application of copyright royalty fees for those items that do not fall under a fair use exemption. At UNCP, we pay most copyright royalties from the library's budget, as part of making things effortless for the faculty members, and to assist departments that would otherwise not have the funds to obtain needed materials. Items are evaluated on a case-by-case basis. A last factor in faculty and student expectations is communication. They want to know what is on reserve, how soon it will be there, and how to access it. Communication of this information is vital in meeting faculty and student expectations. We generally rely on e-mail communications, so that we have documentation as needed; therefore, we considered e-mail integration a key component of a successful reserves system.

\section{EVOLUTION OF RESERVES}

Over my 7-year tenure at UNCP, we have gone through three different reserves system in the search to find one that best fits our needs. What follows is a summary of what we liked and disliked about each system. This summary is not meant to say that any one system is better than another, only that there were specific features that made our current reserves system the best one for us. Each institution needs to evaluate its own needs for functionality in making a decision about which reserves management system will be the most appropriate for the particular environment. 


\section{III-From Innopac to Millennium}

We began using the Innovative's Innopac in1994 for our internal library system. We over time migrated to the Millennium version of the software. Our course reserves management was performed using III through 2006. Overall, this was a very staff-driven system with little processing automation.

LIKES

Catalog integration. Processing of physical reserves was seamless with the use of III, especially with those items that were already owned by the library. It was simple to just change the loan period and location on these items as they were placed in courses in the reserves systems. Faculty-owned materials were easily added, using short bibliographic and item records.

Patron integration. Using the III system made patron access seamless as well, as a separate account was not required. Patrons simply used their regular library account information to access electronic reserves or to find hard copy materials in the catalog.

\section{DISLIKES}

Clunky copies. Processing of electronic reserves in III was a timeconsuming and clunky process. Items would be scanned in as large TIFF files and attached to a short bibliographic/item record for the item. At the end of each semester, all of the TIFFs not to be reused would be deleted from the system. As access services only had the ability to delete the associated item records, this meant regularly providing cataloging with a list of bibliographic records to be deleted. Access to these large files was often problematic for patrons, as we are in a rural area and a large number are on dial-up Internet access. This limited availability of electronic reserves off campus.

No submissions. Submission of reserve requests was not included as part of the system and had to be managed separately using a paper form. One form was used for each course with multiple items included on the same form, making it easy for items and forms to be accidentally separated.

No process tracking. In addition to a lack of a submission process, tracking at what stage of reserves processing particular items were caused a problematic area in efficient workflow. With the variant hours with which the reserves office was staffed, I and other circulation staff often received questions about reserves items that were not fully processed. To answer these questions, we often had to root around the stacks of materials and submission forms in the reserves office to find the correct item. If the item could be found, the next step would be to attempt to determine at what point they were in being readied for access, which often was hard to do. At best, 
we could determine only that it had been submitted, was in processing, and would be ready as soon as possible. It made it difficult for others to assist with processing items already in progress.

No copyright management. Another missing but critical component was a way of managing copyright royalty payments and record keeping. A paper file was kept with the copyright documents for all items requiring a fair use evaluation and/or the payment of copyright royalty payments.

No course integration. III at the time we were using it did not have a component to integrate with online course management systems such as Blackboard. One of our goals with course reserves was to make access seamless, and being able to include reserves materials right inside the online course was something we wanted to achieve.

No communications management. Also lacking was a means of standardizing and regulating communications. Regularly sent messages to faculty regarding reserves had to be kept in a Word file, to be manually copied and pasted into e-mail messages for all faculty communications. Faculty were notified of the readiness of materials under this system-but only if there was a problem with an item or for announcements sent to all faculty.

File-type limitations. Due to the nature of the system, we were limited to physical reserves and large scanned TIFF images. PDFs couldn't be utilized, our electronic databases couldn't be linked to, and digital media items were not able to be included.

No ILL/Acquisitions integration. Though our library had access to the interlibrary and acquisitions modules of III, these were not integrated functionally with the course reserves module. Not only did we not utilize the interlibrary loan module, but requested items not owned by the library could not be transferred to the other modules to be obtained for reserves use. This also had to be done through a manual work-around in which the information was copied out of III and send via e-mail, or sometimes just word of mouth, to the appropriate department to be reentered into the appropriate module on that end.

\section{ERes}

In 2006, the library invested in the Docutek ERes system, which at that time I found to be the best available system for course reserves management. While it had many of the same problems we experienced with III, it also had several important improvements that made it worth the switch. We used the ERes system up to 2008.

\section{LIKES}

Copies. ERes handled electronic reserves much more efficiently and with better accessibility than we had before. Item records were created within 
the software, and PDFs attached after scanning or downloading. The PDFs were much smaller files than the TIFFs we had been using, and were far easier for students off campus to access from their home connections.

File-type possibilities. With the adoption of this new course management software, the types of files allowable for reserves was greatly expanded to include various document, image, and media types. This in turn revolutionized what we were able to offer through reserves services to faculty, turning reserves from books and copies into repositories of course materials of all types.

Some communications. Communications management was a feature of ERes but was not very robust. We had to couple it with a program attached to Microsoft Outlook, called Send Later, in order to set up regularly scheduled automated system e-mails. So while some basic notifications were handled by ERes, a dedicated machine had to be used in order to send the majority of reserves e-mail, making it better but still not seamless.

Hosted. One of the greatest benefits of switching to ERes was the ability to have the system hosted on a remote server maintained by the vendor. This allowed us to focus less on trying to make things work, and more on actually using the system. Other than our problems with Docufax (mentioned below), we had good customer service from Docutek and problems reported were resolved quickly.

\section{DisLIKES}

Several of the disadvantages of the ERes system were the same as those we had with III-a lack of a submissions process, a lack of process tracking, no course integration, and no integration with ILL/Acquisitions. Some of these issues have been addressed in successive releases of ERes, but I cannot speak to their functionality. However, I can note that the areas that have been improved have been updated through separated add-on modules that are not part of the basic system. For example, a submissions improvement can be obtained by purchasing the Docufax module, which allows faculty to fax items to the library, which are received by the library as a PDF that can be attached to the electronic item record in ERes. We did have the Docufax module, but in the 2 years we used ERes, we were never able to get it to work satisfactorily.

Clunky copyright. There was copyright management built into the ERes system as well as some basic reporting, but the processing steps were awkward, it didn't track previous uses of an item, and just wasn't robust enough for our needs.

Catalog integration. In leaving our ILS course reserves module we gained a great deal of functionality but lost integration with our OPAC. This resulted in having to create two records for physical reserve items-one 
for the course list in ERes and one for circulation purposes in III. We did, however, cease creating individual courses in III and now have one course called Current Semester Reserves.

Patron integration clunky. As with the loss of OPAC integration, we lost our patron database, creating the need for a separate log-in for the reserves management system. Each course was given a log-in and password, which the faculty member was responsible for disseminating to students. Staff at circulation and reference spent a great deal of time assisting patrons with access due to forgotten passwords, including often having to determine which password to assist with in the first place.

\section{Ares (2008-Present)}

LIKES

The Ares course reserves system met our needs far better than any of our previously used software products. Several features of Areas were found in ERes, but were made more robust-with internal scanning included, even more file type possibilities, and additional hosting services, support, and training opportunities.

Submissions. A means of processing submissions was one of the biggest advantages gained by switching to the Ares system. Using a series of publically accessible Web pages, faculty members can create an account, add courses, and submit reserve requests for those courses for a number of different item types. This creates records in the Ares system that are then routed to one of a number of queues according to internally specified routing rules.

Copyright. Copyright processing and reporting was also improved. In the copyright processing queue, a direct connection to our Copyright Clearance Center (CCC) account allows us to see if an item has been used before; see how much royalties are, if necessary; and place the order for all but items not available through the CCC from within Ares. For those latter items, Ares provides_as Docutek did-templates for communications to be sent directly to publishers. Custom reporting is possible, as well as the inclusion of standard reports on copyright spending.

Process. Items are moved from one queue to another in the process until they are completed. This makes tracking the progress of a particular item effortless for staff and for faculty, as faculty can see an item's current status simply by logging into their account. Staff can easily pick up processing where an item was left off, and workloads can be divided as necessary without sacrificing efficiency.

Course integration. With the Ares Blackboard plug-in, we are able to list course reserve items directly in a Blackboard course, without having to be granted proxy access to each course. This seamless integration makes access 
for students and faculty better than any previous system we have used. We are in the process of implementing this feature now, and are very excited that students will no longer have to go to multiple systems to complete their coursework.

Communications integration. E-mail communications are built into Ares and notices are sent not only to notify faculty and students of newly available items, problems with processing, and account information, but also scheduled e-mails can be stored and sent. Since we send out the same emails at the beginning, middle, and end of each semester to all faculty, this feature works very well for us and has eliminated the need for a separate e-mail system to perform this function.

ILL/Acquisitions integration. Since Ares comes from Atlas Systems, the creators of the ILLiad interlibrary system, not only are the two systems alike in functionality and operations, but there is also the ability to forward reserve requests to ILLiad for fulfillment, if the material is not available. This greatly increases the efficiency in dealing with these types of requests by creating a seamless integration of the two systems. Less seamless, but still highly beneficial, is the ability to route reserve requests to Acquisitions for fulfillment. This generates an e-mail in Ares that is sent to the addresses you specify in the system, and the item is routed to the appropriate holding queue. Of course, since there isn't an Acquisitions system compatible with Ares, these records have to be manually updated when they are fulfilled, but it is still a huge time-saver.

Patron integration. This was again made possible through the use of lightweight directory access protocol. We have not yet implemented this functionality, as it requires a cooperative approach between several campus departments, but that is not a system limitation, it is an institutional one.

Brandable. Ares's public Web pages are customizable, much like the Web pages are for ILLiad. We were able to put our own logo on them, set our own colors, add requests types, and generally make any customizations we felt we needed to make the system fit our needs.

\section{DISLIKES}

We have found ourselves very happy with the Ares system. Its only real drawback is its lack of integration with our OPAC, such as we mentioned was the case with ERes. Having to create duplicate item records is not only inefficient, but increases chances of error and other problems. It would be great to see this as an area of enhancement, as we believe it is the one piece of key functionality missing from the Ares. Another enhancement we would like to see is the ability to scan a PDF within Ares, which has scanning capabilities but does not create PDF files. This is less critical though, as PDF files are easily attached to item records in Ares, the only drawback being having to actually do the scanning in Adobe Acrobat. 


\section{FUTURE ENDEAVORS}

Our quest for a reserves system that met our needs was long and sometimes frustrating, but in the end we believe we ended up with the best solution to meet the needs of our faculty, students, and staff. The journey continues now in the search to find even more ways to bring our services seamlessly to our patrons wherever they happen to be, rather than creating hoops to jump through that hinder access. As such, our next big endeavor is social media integration-finding ways to integrate Ares into social networking systems so that patrons have ease of access wherever they go. To this end we are beginning to make inroads into Facebook and Second Life- the two social networking systems we are finding most in use by our students. We're exploring ways to integrate with their cell phone technologies as well. Rather than approaching course reserves as them coming to us for a service, we are bringing the service to them-individualizing it. Like our university motto says, we are where learning gets personal. 
Copyright of Journal of Access Services is the property of Taylor \& Francis Ltd and its content may not be copied or emailed to multiple sites or posted to a listserv without the copyright holder's express written permission. However, users may print, download, or email articles for individual use. 